\title{
Quantitative Analysis of Carbon in Silicon Carbide Coated with Carbon
}

\author{
Hongrim Lee, ${ }^{1}$ Junsu Kim, ${ }^{2}$ and Jondo Yun ${ }^{1, \star}$ \\ ${ }^{1}$ Department of Nano Science and Engineering, Kyungnam University, Woryeong-dong, Masanhabpo-gu, \\ Changwon 631-701, Korea \\ ${ }^{2}$ Department of Advanced Engineering, Graduate School, Kyungnam University, Woryeong-dong, Masanhabpo-gu, \\ Changwon 631-701, Korea
}

\begin{abstract}
Nonconductive specimens for scanning electron microscopy or X-ray microanalysis are coated with conductive carbon in order to reduce charging. But carbon film absorbs X-ray fluxes causing errors in measuring chemical composition. Especially when the carbon content is measured, carbon coating not only blocks X-rays but also becomes a source of carbon X-rays. It is thus necessary to determine how much errors are induced by carbon coating, and how thick coating is allowed for the accurate measurement. In this study, quantitative analysis of carbon on silicon carbide with carbon coating films was attempted by electron probe microanalyzer. It was found that measured carbon content increased in a nonlinear manner up to $40 \%$ with a film thickness, whereas silicon content decreased slightly. Carbon X-ray intensity was determined by computer simulation, which increased in a linear manner with the thickness. The discrepancy was due to a nucleation and growth of islands and thus a change of density with a thickening of coating film.
\end{abstract}

Key words: electron probe microanalysis, carbon coating, silicon carbide, carbon content, silicon content, X-ray intensity, density

\section{INTRODUCTION}

Nonconductive samples for scanning electron microscopy or X-ray microanalysis are usually coated with conductive carbon in order to reduce charging (Goldstein et al., 2003; Yun et al., 2005). The charging due to an insufficient electrical conductivity of specimen affects the results of quantitative electron probe microanalysis (Bastin \& Heijligers, 2004). Thick coating film blocks the X-ray fluxes causing errors in measuring chemical compositions (Jercinovic \& Williams, 2005). When specimens are coated with a heavy element like gold, platinum, or palladium, the effect is greater. Especially when the carbon content is measured from the carboncontaining specimens, carbon coating gives a negative effect on the measurement by not only blocking X-rays, but also becoming a generation source of carbon X-rays. However, carbon coating is sometimes the only option, particularly in the case of cultural artifacts, or standards for the quantitative analysis. It is then necessary to determine how much errors are made because of the coating, and how thick coating is allowed for the chemical composition measurement in the acceptable error range. Kerrick et al. (1973) examined the loss of X-ray intensity as a function of carbon film thickness. They examined X-rays of fluorine, sodium, silicon, iron, and strontium, but not that of carbon. They found that X-ray intensity errors of up to $4 \%$ were possible with a film thickness difference of $20 \mathrm{~nm}$.

In this study, we examined the errors in measurement of carbon and silicon contents in silicon carbide specimen coated with carbon films in various thicknesses by X-ray

() MICROSCOPY SOCIETY OF AMERICA 2013

${ }^{\star}$ Corresponding author. E-mail: jdyun@kyungnam.ac.kr microanalysis. We also determined carbon and silicon contents by computer simulation and compared these values with those obtained from experiments.

\section{Materials And Methods}

Alpha silicon carbide single crystal wafers were used for the specimens for the analysis. The specimens were coated with carbon using thermal evaporator. By changing the period of time for the thermal evaporation, the coating films with thicknesses in a range of $8-35 \mathrm{~nm}$ were obtained. The thickness of coating film was measured with a spectroscopic ellipsometer (Nanoview, Korea). The carbon contents in silicon carbide specimens coated with carbon were measured by electron probe microanalyzer. The measuring conditions were $15 \mathrm{kV}$ of accelerating voltage, and $10 \mathrm{nA}$ of beam current. The intensities of X-ray generation and emission from the specimen were also determined by computer simulation using DTSA-II software (written by Dr. N. Ritchie, NIST, USA) at each thickness of $10,20,30$, and $40 \mathrm{~nm}$ of carbon film and at each density of $0.2,0.5,0.8,1.1$, and $1.4 \mathrm{~g} / \mathrm{cm}^{3}$. Simulations were repeated five times for each condition, and the X-ray intensity values obtained were averaged. The standard deviations were $<5 \%$ of average values.

\section{Results And Discussions}

Carbon content measured increased with a thickness of carbon film on silicon carbide specimen because of an increase in X-ray emission from coating film (Fig. 1a). But silicon content measured decreased with a thickness because of an increase in X-ray absorption by the coating film 


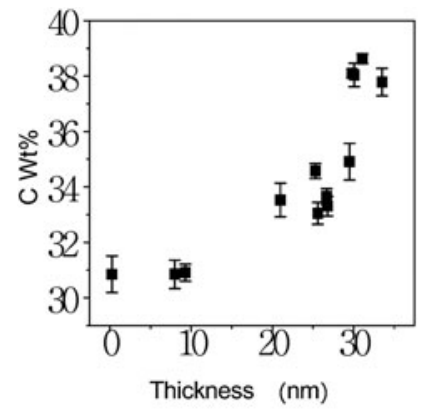

(a)

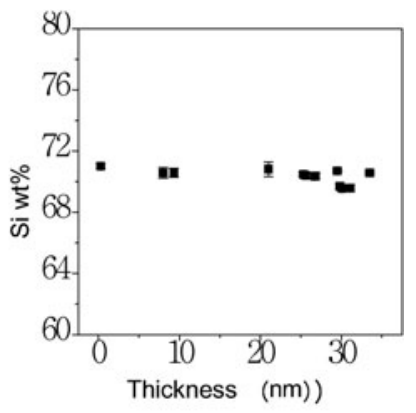

(b)

Figure 1. Change in (a) carbon content and (b) silicon content in silicon carbide specimen measured by electron probe microanalyzer with a change in thickness of carbon film.

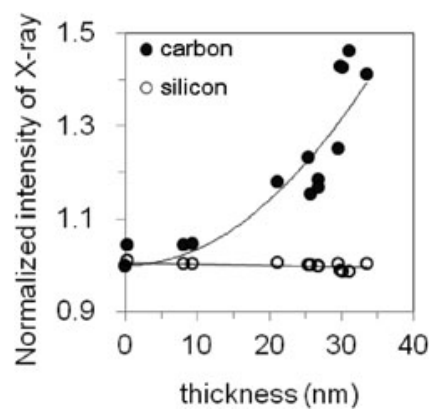

Figure 2. Normalized intensities of carbon and silicon X-rays obtained by electron probe microanalyzer from the silicon carbide samples.

(Fig. 1b). As carbon as an absorption source was a light element, the decreasing rate was low.

The carbon and silicon contents measured from the specimens with films of various thicknesses were normalized by those from the specimen without coating, as shown in Figure 2. The increasing rate of carbon content was $<5 \%$ at $11 \mathrm{~nm}$ thickness of coating film, but increased rapidly as the thickness increased further, reaching $40 \%$ at $35 \mathrm{~nm}$. On the contrary, decreasing rate of silicon content was low, being $<2 \%$ even at $35 \mathrm{~nm}$.

The intensities of generated and emitted X-rays were computer simulated. Normalized intensities of emitted X-rays of carbon and silicon were shown in Figure 3. In case of carbon X-rays, simulated intensity of emitted X-rays increased in a linear manner as the thickness increased from 0 to $40 \mathrm{~nm}$ for each density. Simulation results also showed that the interaction width in horizontal plane for the X-ray generation changed barely with a thickness change. Then interaction volume and the amount of X-ray generation must increase with thickness in a linear manner. As the density increased from 0.2 to 1.4 , the simulated intensity of emitted $\mathrm{X}$-rays also increased. It is due to an increase in the number of X-ray generation sources. In case of silicon X-rays, the intensity decreased slightly with the thickness and density.

The experimental data are shown for the comparison with the simulated data in Figure 3. The trend line of experimental data was not linear and does not fit any trend line of simulated data with a film density in a range be-

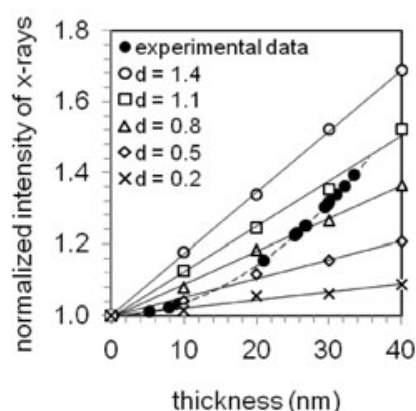

(a)

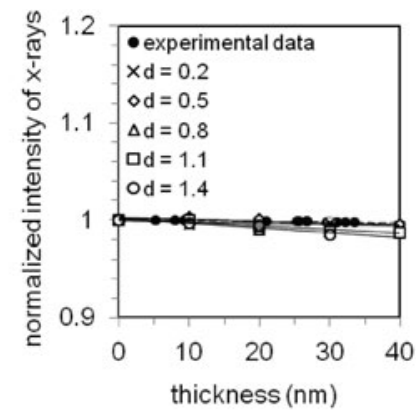

(b)
Figure 3. Simulated and normalized intensities of emitted (a) carbon X-rays and (b) silicon X-rays from the specimen with a carbon film of various thicknesses and densities. Experimental data are also shown for the comparison.

tween 0.2 and 1.4. The reason for the discrepancy may be due to the density change with a thickness. It has been known that coating film is formed on a substrate in one of the three growth modes: Volmer-Weber or 3D island growth mode, Frank-van der Merwe or layer-by-layer growth mode, and Stranski-Krastanov or 3D island growth on top of predeposited monolayers mode, depending on the type and size of the interaction energies and misfit energy between atoms in substrate and film (Lorenz \& Staikov, 1995). Islands are formed on substrates by nucleation, growth, and coalescence (Goldstein et al., 2003). It was reported that carbon film grew by forming islands and their coalescence (Durand et al., 1998; Maheswaran et al., 2011). It is not surprising to find that the density of film changes as it grows thicker.

The experimental data showed that the error of intensity of X-rays were 5 or $10 \%$ at 11 or $17 \mathrm{~nm}$ of thickness. If one wants to get accurate results with an error $<5 \%$, one has to coat the sample with a carbon film of thickness $<11 \mathrm{~nm}$.

\section{CONCLUSIONS}

The effect of carbon coating on the quantitative analysis of silicon carbide specimens coated with carbon was examined. It was found that carbon contents increased up to $40 \%$ in a nonlinear manner as a film thickness increased to $35 \mathrm{~nm}$ and that silicon content decreased $<2 \%$. The simulation result showed that X-ray intensity increased in a linear manner with a coating thickness. The discrepancy was due to the change of density with a thickness of the coating film. The minimum thickness of carbon coating film for the acceptable error range was $11 \mathrm{~nm}$. Above that thickness, the carbon compositional data may have errors $>5 \%$.

\section{ACKNOWLEDGMENTS}

The work was supported by the Kyungnam University Research Fund 2011. The authors are grateful to Mr. Changhun Hwang for his technical assistance. 


\section{REFERENCES}

Bastin, G.F. \& Heijligers, H.J.M. (2004). Quantitative electron probe microanalysis of non-conductive specimens. Microsc Microanal 10, 733-738.

Durand, H.-A., Sekine, K., Еtoh, K., Ito, K. \& Kataoka, I. (1998). Influence of induced defects on the ultra thin film growth by low energy ion beam deposition. Int Conf Ion Implantn Technol Proc 2, 929-932.

Goldstein, J.I., Lyman, C.E., Newbury, D.E., Lifshin, E., EchLin, P., Sawer, L., Joy, D.C. \& Michael, J.R. (2003). Scanning Electron Microscopy and X-Ray Microanalysis, chapter 15. New York: Kluwer Academic/Plenum Publishers.

Jercinovic, M.J. \& Williams, M.L. (2005). Analytical perils and progress in electron microprobe trace element analysis applied to geochronology: Background acquisition, interferences, and beam irradiation effects. Amer Mineralogist 90, 526-546.

Kerrick, D.M., Eminhizer, L.B. \& Villaume, J.F. (1973). The role of carbon film thickness in electron microprobe analysis. Amer Mineralogist 58, 920-925.

Lorenz, W.J. \& Staikov, G. (1995). 2D and 3D thin film formation and growth mechanisms in metal electrocrystallization-An atomistic view by in situ STM. Surf Sci 335, 32-43.

Maheswaran, R., Ramaswamy, S., Thiruvadigal, D.J. \& GoPALAKRISHNAN, C. (2011). Systematic study of various stages during the growth process of diamond-like carbon film by atomic force microscopy. J Non-Cryst Solids 357, 1710-1715.

Yun, J., YAng, C., Kim, J. \& LeE, S. (2005). Scanning Electron Microscopy and X-Ray Microanalysis. Seoul, Korea: Cheongmungak. 